\title{
Refractory Hypodynamic Shock: Role of Insulin in Toxodromes
}

\author{
Nilma Malik ${ }^{\mathrm{a}, \mathrm{b}}$, Vishwanath Pattan ${ }^{\mathrm{a}}$, Hongxiu Luo ${ }^{\mathrm{a}}$, Waqas Jehangir ${ }^{\mathrm{a}}$, \\ Shuvendu Sen ${ }^{a}$, Abdalla Yousif ${ }^{a}$
}

\begin{abstract}
Calcium channel blocker (CCB) and beta blocker (BB) toxicities are considered the most common lethal prescription drug overdoses. Awareness regarding implementation of insulin-euglycemia state in treatment of anti-hypertensive overdose is limited in clinical practice. We report a similar case of a 56 years old male who presented with $\mathrm{CCB}$ and $\mathrm{BB}$ overdose and responded exceptionally well to aforementioned regimen. This case further emphasizes that it is imperative for clinicians to recognize that prompt initiation of high-dose insulin therapy has significant morbidity and mortality benefits in these toxodromes.
\end{abstract}

Keywords: Insulin; Hypodynamic; Toxodromes; Euglycemia

\section{Introduction}

Most cases of poisoning have limited information and management decisions are based on presumed drug overdose. $\mathrm{Pa}$ tients often present with altered mentation or hemodynamic instability. Application of high-dose insulin in treatment of anti-hypertensive overdose is not frequently practiced in clinical settings. We report a case of 56 years old male presenting with refractory hypodynamic shock due to mixed calcium channel blocker (CCB) and beta blocker (BB) toxicity. The clinical course merits the successful outcome with implementation of insulin-euglycemia state.

Manuscript accepted for publication June 27, 2014

${ }^{a}$ Department of Internal Medicine, Raritan Bay Medical Center, 530

New Brunswick Avenue, Perth Amboy, NJ 08861, USA

${ }^{\mathrm{b}}$ Corresponding Author: Nilma Malik, Department of Internal

Medicine, Raritan Bay Medical Center, 530 New Brunswick Avenue,

Perth Amboy, NJ 08861, USA. Email: nilmamalik1@gmail.com

doi: http://dx.doi.org/10.14740/jmc1851w

\section{Case Report}

A 56 years old male was admitted to hospital after he was found comatose with empty bottles of atenolol, amlodipine, verapamil and clonidine. Upon presentation, his heart rate was $35 / \mathrm{min}$, blood pressure was $58 / 40 \mathrm{~mm} \mathrm{Hg}$, RR was $16 /$ min, $\mathrm{T}$ was $98.3^{\circ} \mathrm{F}$ and $\mathrm{So}_{2}$ was $98 \%$. Patient received naloxone, atropine, intravenous fluids, glucagon, calcium gluconte and gastric lavage but bradycardia and hypotension persisted. Thereafter he was placed on transcutaneous pace maker, intubated and started on vasopressors. Labs were significant for blood glucose $7.21 \mathrm{mmol} / \mathrm{L}$ (n: $3.88-6.38 \mathrm{mmol} / \mathrm{L}$ ), BUN $1.88 \mathrm{mmol} / \mathrm{L}$ (n: $0.33-1.10 \mathrm{mmol} / \mathrm{L}$ ), creatinine 0.13 $\mathrm{mmol} / \mathrm{L}$ (n: $0.03-0.06 \mathrm{mmol} / \mathrm{L}$ ), bicarbonate $11 \mathrm{mEq} / \mathrm{L}$ (n: $22-28 \mathrm{mEq} / \mathrm{L}$ ). Troponins and urine drug toxicology were negative. CXR and CT of head were unremarkable.

Despite the resuscitative efforts the patient had refractory hypotension and bradycardia with intrinsic HR 30 - 40/ min. He was eventually started on high-dose insulin drip at $0.5 \mathrm{U} / \mathrm{kg} / \mathrm{h}$, dextrose $50 \%$ at $50 \mathrm{~mL} / \mathrm{h}$. The insulin drip was titrated to a goal MAP $>70 \mathrm{~mm} \mathrm{Hg}$ and heart rate $>80 / \mathrm{min}$. Also serum glucose and potassium levels were monitored every $30 \mathrm{~min}$ and D50 titrated to maintain blood glucose between 6.10 and $7.76 \mathrm{mmol} / \mathrm{L}$ (Fig. 1). The patient responded exceptionally well to the high-dose insulin regimen. His heart rate, blood pressure and acidemia improved. He was taken off the pacemaker, vasopressors and insulin drip by day 5 and eventually extubated and discharged to subacute rehabilitation center after stabilization.

\section{Discussion}

Most cases of poisoning have limited information regarding specific drugs and doses. Therefore, management decision is based on clinical presentation and presumed drug overdose. $\mathrm{CCB}$ and $\mathrm{BB}$ toxicity is the most frequently reported lethal prescription medication overdosing that causes dysarrthymias, shock and sudden cardiac collapse.

In 2006, there were 9,041 single BB exposures reported to poison centers in the United States. Of these, there were 


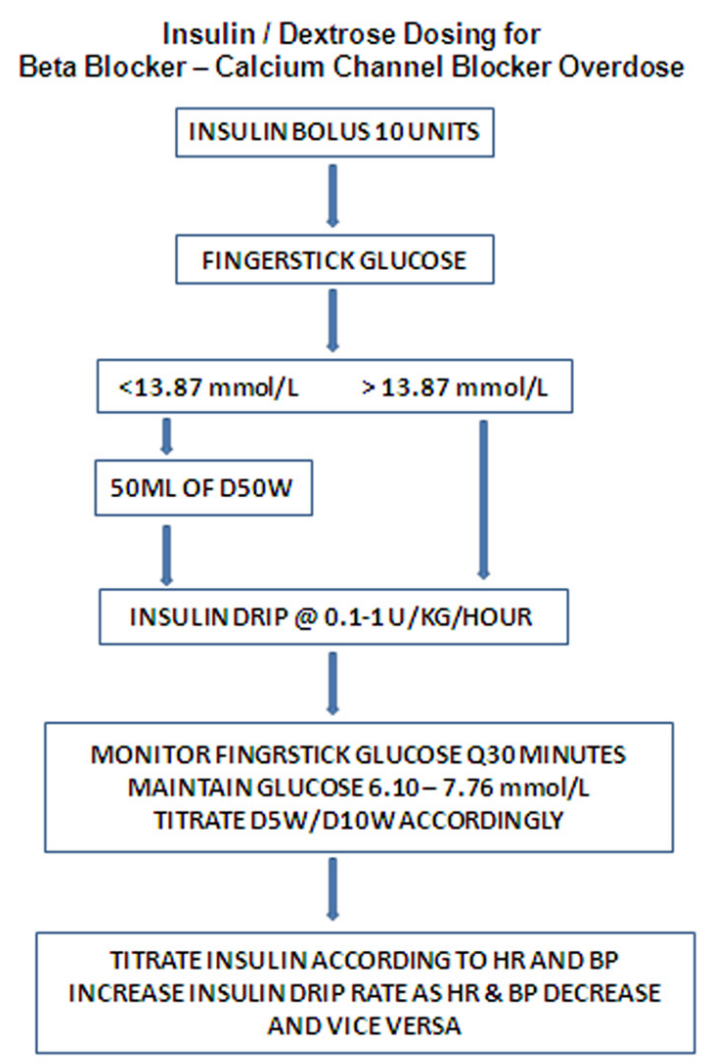

Figure 1. Insulin/dextrose dosing for BB-CCB overdose.

613 moderate or major adverse outcomes and four deaths [1]. Nevertheless, in 2011 almost 5,408 single exposures to $\mathrm{CCB}$, resulted in 25 deaths and 90 major outcomes were reported [2].

Under physiological conditions myocardium generates energy through mitochondrial oxidation of long chain fatty acids $(60-70 \%)$, glucose $(20 \%)$ and lactate $(10 \%)$. During the state of cardiac stress, energy generation is switched from preferred fatty acid substrate to glucose [3]. CCB and BB toxicity produces metabolic derangements that lead to hypoperfusion and acidemia. This acidemia impairs insulin release and glucose uptake and utilization in the myocardium. Insulin infusion increases glucose and lactate uptake by myocardium and enhances glycolysis promoting excitationcontraction coupling and contractility [3]. Insulin-mediated inotropy is not catecholamine-mediated, therefore is not affected by BB and CCB [4]. It exhibits mitogenic and growth promoting effect which leads to physiological myocardial hypertrophy and increased cardiac contraction [5]. Moreover retrospective analysis of similar case studies has shown that immediate treatment with high-dose insulin has significant morbidity and mortality benefits [6].

Since combination of anti-hypertensives is often prescribed in primary care setting, a high incidence of toxicity ensues. Currently we do not have means to quantify the lev- els of $\mathrm{CCB}$ and $\mathrm{BB}$ as in contrast to other cardiotoxic medications such as digoxin and phenytoin. Perhaps it is reasonable school of thought to take an initiative to devise methods to quantify the levels of medications or its metabolites in the blood or urine.

Therefore, it is crucial to have high clinical index of suspicion for CCB and BB overdose and insulin-euglycemia state should be rapidly achieved.

\section{Funding}

None.

\section{Conflict of Interest}

None.

\section{References}

1. Bronstein AC, Spyker DA, Cantilena LR, Jr., Green J, Rumack BH, Heard SE. 2006 Annual Report of the 
American Association of Poison Control Centers' National Poison Data System (NPDS). Clin Toxicol (Phila). 2007;45(8):815-917.

2. Watson WA, Litovitz TL, Rodgers GC, Jr., KleinSchwartz W, Youniss J, Rose SR, Borys D, et al. 2002 annual report of the American Association of Poison Control Centers Toxic Exposure Surveillance System. Am J Emerg Med. 2003;21(5):353-421.

3. Nickson CP, Little M. Early use of high-dose insulin euglycaemic therapy for verapamil toxicity. Med J Aust. 2009;191(6):350-352.

4. Megarbane B, Karyo S, Baud FJ. The role of insulin and glucose (hyperinsulinaemia/euglycaemia) therapy in acute calcium channel antagonist and beta-blocker poisoning. Toxicol Rev. 2004;23(4):215-222.

5. Sasaoka T, Ishiki M, Sawa T, Ishihara H, Takata Y, Imamura T, Usui I, et al. Comparison of the insulin and insulin-like growth factor 1 mitogenic intracellular signaling pathways. Endocrinology. 1996;137(10):44274434.

6. Lheureux PE, Zahir S, Gris M, Derrey AS, Penaloza A. Bench-to-bedside review: hyperinsulinaemia/euglycaemia therapy in the management of overdose of calciumchannel blockers. Crit Care. 2006;10(3):212. 